Research Article

\title{
Dynamic Analysis of Percussion Drilling System under Harmonic Impact
}

\author{
Yijin Zeng, ${ }^{1}$ Shidong Ding, ${ }^{1}$ Jinchao Xu ${ }^{D},{ }^{2}$ Qunai Hu, ${ }^{1}$ and Xiaojie Cui ${ }^{1}$ \\ ${ }^{1}$ State Key Laboratory of Shale Oil and Gas Enrichment Mechanisms and Effective Development, Beijing 100083, China \\ ${ }^{2}$ School of Mechanical Science and Engineering, Northeast Petroleum University, Daqing 163318, China \\ Correspondence should be addressed to Jinchao Xu; xujinchao2005@163.com
}

Received 28 May 2020; Revised 22 April 2021; Accepted 14 June 2021; Published 23 June 2021

Academic Editor: Wenjun Huang

Copyright (c) 2021 Yijin Zeng et al. This is an open access article distributed under the Creative Commons Attribution License, which permits unrestricted use, distribution, and reproduction in any medium, provided the original work is properly cited.

As a new efficient rock-breaking technology, harmonic impact drilling technology has received great attention, but the research on its rock-breaking mechanism is insufficient, which limits its development. Based on the theory of vibration, a simplified model of high-frequency harmonic vibration impact system is established in this paper. The numerical model was solved by Matlab and the motion equations of drill bit and rock at different stages of motion are obtained, respectively. Based on the factor analysis of the mathematical model, the dynamic characteristics of the impact system under harmonic excitation are studied. Finally, numerical simulations are carried out to further analyze the drilling effect of harmonic impact drilling and verify the correctness of the simplified model. The results show that when the excitation frequency equals the resonance frequency of rock, the vibration displacement of rock reaches the peak value. The drilling speed is greatly increased by harmonic impact drilling compared with conventional drilling.

\section{Introduction}

Harmonic impact drilling technology is an emerging efficient rock-breaking method that is developed by the Centre for Applied Dynamics Research (CADR) at the University of Aberdeen to improve the rate of penetration in hard formation $[1,2]$. The technology is realized by applying harmonic impact to the rock combining the appropriate drilling pressure and rotational speed. In particular, when the impact frequency of the system is equal to the natural frequency of the rock, the rock will resonate, which is called the Resonance Enhanced Drilling (RED).

Since the technology was proposed, lots of studies have been done by a number of researchers [3-5]. At present, the major research work is concerned with the following aspects. On the one hand, it focused on the dynamic characteristics of the impact system [6-8]. A variety of dynamic models of drill string were presented to analyze the motion state of drilling system. The authors of [8] undertook the modeling of the vibroimpact drilling system and presented the results of the numerical analysis and comparison between two selected models. The study in [9] proposed and investigated a new method of vibrational energy transfer from highfrequency low-amplitude to low-frequency high-amplitude mechanical vibrations for the purpose of percussive drilling.

On the other hand, a series of experimental tests are conducted indoor [10-12]. The ultrasonic test on artificial sandstones and materials of drill tools is carried out indoor in [13], and the FFT transform method is adopted to obtain rocks' resonance frequencies. Aiming to evaluate the applicability of RED technology to coring operations, a series of coring experiments on sandstone and granite are carried out on a specially designed vertical laboratory drilling rig and improvements in penetration rates up to $180 \% \mathrm{com}$ pared to conventional coring [14]. By comparison with the rock-breaking effect of conventional drilling, the advantages of harmonic impact drilling technology were verified.

In addition, there were a few researches on the fundamental rock-breaking mechanism of the technology. Li et al. $[15,16]$ analyzed the rock-breaking mechanism of drill tool under harmonic vibroimpacting both theoretically and experimentally. Based on the principle of least action [17], 
microvibration equation of rock was introduced. Aspects of impact characteristic parameters $[15,18]$ and rock mechanics parameters $[19,20]$ were mainly considered in this part.

The innovation of the paper is the dynamic analysis of percussion drilling system under the harmonic impact which is conducted from both percussion drilling model and numerical simulations, and the drilling effect of the harmonic impact technology is proved.

\section{Simplified Model}

In order to further analyze the interaction between the drill bit and rock, the rock-breaking model of high-frequency harmonic vibration is simplified, and the motion behavior between the drill bit and rock is analyzed separately. The physical model includes the bit mass system, the component system of impact loading, and the friction slider system representing the rock, which are shown in Figure 1. The mass of the bit is $m$, the static load exerted on the bit by the exciter is $F_{s}$, and the dynamic load exerted on the bit is $F_{0} \cos (\Omega t+\varphi)$. The distance from the initial position of the bit to the rock surface is $G$. The rock is simulated by viscoelastic sliding block. The spring with stiffness of $k$ and the damper with damping coefficient of $c$ are used to consider the elastic behavior and damping of the rock, respectively.

When the force $P_{c}$ applied to the rock surface by the drill bit exceeds the critical force of the slider $P_{r}$, the slider begins to move downward to simulate drilling. The displacement of the bit is $x_{\mathrm{m}}$, the displacement of the rock surface is $x_{t}$, and the displacement of the slider is $x_{b}$.

There are three different motion stages for drill bit in the simplified physical model, and the specific analysis process is as follows.

2.1. The Stage When the Drill Bit Is Not in Contact with the Rock. At this stage, the drill bit is not in contact with the rock surface. According to Newton's second law, the motion differential equation of the whole system can be expressed as

$$
\left\{m \ddot{x}_{m}=F_{s}+F_{0} \cos (\Omega t+\phi), \dot{x}_{b}=0 .\right.
$$

At this point, the force $P_{c}$ exerted by the drill on the rock surface is

$$
P_{c}=c\left(\dot{x}_{t}-\dot{x}_{b}\right)+k\left(x_{t}-x_{b}\right)=0,
$$

where $m$ is the bit weight, $\mathrm{kg} ; \ddot{x}_{\mathrm{m}}$ is the acceleration of the bit, $\mathrm{m} / \mathrm{s}^{2} ; x_{t}$ is the displacement of the rock surface, $\mathrm{m} ; x_{b}$ is the displacement of the slide block, $\mathrm{m}$; $G$ is the distance between the initial position of the bit and the rock surface, $\mathrm{m} ; \dot{x}_{\mathrm{t}}$ is the movement speed of the rock surface, $\mathrm{m} / \mathrm{s} ; \dot{x}_{b}$ is the movement speed of the slide block, $\mathrm{m} / \mathrm{s} ; c$ is the spring damping coefficient, $\mathrm{N} \cdot \mathrm{m} / \mathrm{s} ; k$ is the spring stiffness, $\mathrm{N} / \mathrm{m} ; P_{c}$ is the force exerted by the bit on the rock surface, $\mathrm{N} ; F_{0}$ is the amplitude of dynamic excitation force, $\mathrm{N} ; F_{\mathrm{s}}$ is the static load, $\mathrm{N} ; \Omega$ is excitation frequency, $\mathrm{rad} / \mathrm{s} ; \varphi$ is phase angle, $\mathrm{rad} ; t$ is time, s.
2.2. The Stage When the Drill Bit Is in Contact with the Rock without Drilling. At this stage, the drill bit is in contact with the rock surface, but the slider system does not move. Similarly, according to Newton's second law, the motion differential equation of the whole system is as follows:

$$
\left\{m \ddot{x}_{m}+c\left(\dot{x}_{t}-\dot{x}_{b}\right)+k\left(x_{t}-x_{b}\right)=F_{s}+F_{0} \cos (\Omega t+\phi), \dot{x}_{b}=0 .\right.
$$

At this point, the relationship between rock surface displacement and drill bit displacement is $x_{t}=x_{m}-G$, and the force exerted by the drill bit on the rock surface is

$$
k\left(x_{t}-x_{b}\right)+c\left(\dot{x}_{t}-\dot{x}_{b}\right)-P_{r}=0,
$$

where $P_{r}$ is the critical force of the slider, $\mathrm{N}$.

2.3. Drilling into Rock. When the drill bit is in contact with the rock surface and the slider system generates motion, the motion differential equation of the whole system is

$$
m \ddot{x}_{m}+c\left(\dot{x}_{t}-\dot{x}_{b}\right)+k\left(x_{t}-x_{b}\right)=F_{s}+F_{0} \cos (\Omega t+\phi) .
$$

At this point, the relation between rock surface displacement and drill bit displacement is $x_{t}=x_{m}-G$, and the force exerted by the bit on the rock surface is also shown in equation (4).

\section{Analysis of Influencing Factors of the Dynamic Model}

The dynamic model of high-frequency harmonic vibration impact drilling is numerically calculated by Matlab software, and the influence of rock stiffness, damping, impact frequency, and other parameters on drilling effect is analyzed.

3.1. Noncontact Stage between Drill and Rock. At this stage, the drill bit is not in contact with the rock; that is, the drill bit does not drill. At this point, the distance between the rock surface and the slide $x_{t}-x_{b}$ is constant. Its value is determined by the stiffness of rock $k$ and the damping of rock $c$. Therefore, the displacement curve of rock surface with time is a straight line. As shown in Figure 2, rock 1, rock 2, and rock 3 are sandstone, limestone, and granite, respectively.

3.2. Stage of the Bit Contact with Rock without Drilling. At this stage, the simple harmonic vibration impact force of the drill bit acting on the rock surface is less than the critical force of the rock, and the rock only produces viscoelastic resistance. At this point, only the rock surface produces movement displacement, while the slider does not generate movement.

3.2.1. Influence of Stiffness on Rock Motion. Different rock stiffness $k$, the same impact frequency $\Omega$, system damping $c$, rock mass $m$, dynamic excitation force $F$, and rock critical 


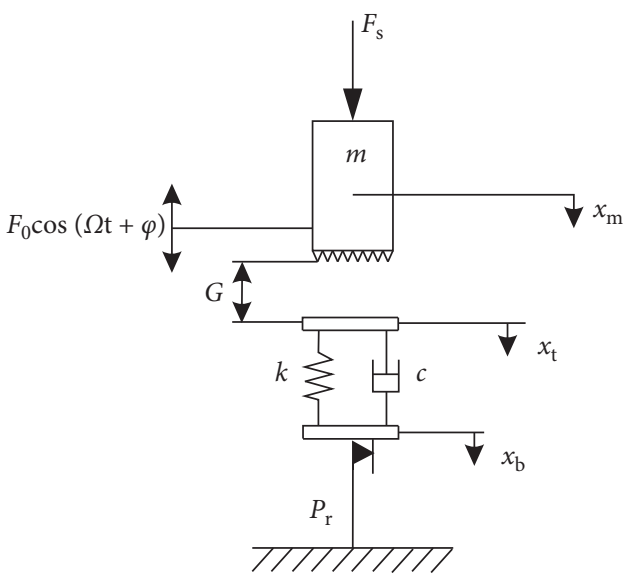

Figure 1: Simplified rock-breaking model between drill bit and rock.

force $P_{r}$ were used to analyze rock movement displacement and velocity under simple harmonic vibration excitation. The specific calculation parameters are shown in Table 1.

Figure 3 shows the relation curves of rock surface movement displacement and velocity with time under different stiffness. As shown in the figure, under the impact of simple harmonic vibration, the rock surface also presents the trend of simple harmonic vibration. The smaller the stiffness of the rock is, the greater the maximum displacement and velocity the rock can achieve. This is because, under the condition of the same harmonic excitation force and the same rock mass, the smaller the rock stiffness is, the easier the rock surface is to produce deformation and motion. At the same time, because of the existence of damping, the rock surface motion decay with time.

3.2.2. Influence of Damping on Rock Motion. Different rock damping $c$, the same impact frequency $\Omega$, rock stiffness $k$, rock mass $m$, dynamic excitation force $F$, and rock critical force $P_{r}$ were used to analyze the change law of rock movement displacement and velocity under simple harmonic vibration excitation. The specific calculation parameters are shown in Table 2.

Figure 4 shows the relationship curves of rock surface displacement and velocity with time under different damping conditions. As shown in the figure, the smaller the damping of the rock is, the greater the range of motion generated on the rock surface is, the faster the movement is, and the longer the movement lasts. When the rock damping coefficient reaches 1.5, the system is in an overdamped state, and most of the impact energy of the drill on the rock is consumed by the damping, so the rock surface hardly moves.

3.2.3. Influence of Excitation Frequency on Rock Motion. Different impact frequencies $\omega$, the same rock damping $c$, rock stiffness $k$, rock mass $m$, dynamic excitation force $F$, and rock critical force $P_{r}$ were used to analyze the variation law of rock motion velocity under simple harmonic vibration excitation. The specific calculation parameters are shown in Table 3.
As shown in Figure 5, the movement velocity of the rock surface varies in a simple harmonic manner with the excitation frequency. Under different excitation frequencies, the maximum velocity of rock surface is different, which is related to the natural frequency of rock. The closer the excitation frequency is to the natural frequency of the rock, the greater the displacement and velocity of the rock surface will be. When the excitation frequency is equal to the natural frequency of the rock, the rock reaches harmonic, and the corresponding motion displacement and velocity will reach the peak.

\subsubsection{Influence of Dynamic Excitation Force on Rock Motion.} Different dynamic excitation force $F$, the same rock damping $c$, rock stiffness $k$, rock mass $m$, impact frequency, and rock critical force $P_{r}$ were used to analyze the variation law of rock motion velocity under simple harmonic vibration excitation. The specific calculation parameters are shown in Table 4.

As shown in Figure 6, the movement velocity of the rock surface also changes periodically with the impact force of simple harmonic vibration. At the same excitation frequency, the velocity of rock surface increases with the increase of dynamic excitation force. The greater the excitation force is, the greater the maximum movement speed that can be achieved on the rock surface.

3.3. Drilling Stage. In this stage, the impact force of simple harmonic vibration acting on the rock surface is greater than the critical force of the rock, and the rock has plastic deformation; and both the rock surface and the slide have motion displacement. The magnitude of motion displacement is affected by the rock damping and critical force and changes with time.

Different rock damping $c$ and rock critical force $P_{r}$, as well as the same rock stiffness $k$, rock mass $m$, dynamic excitation force $F$, and impact frequency $\omega$, are used to analyze the change law of rock movement displacement under simple harmonic vibration excitation. The specific calculation parameters are shown in Table 5. 


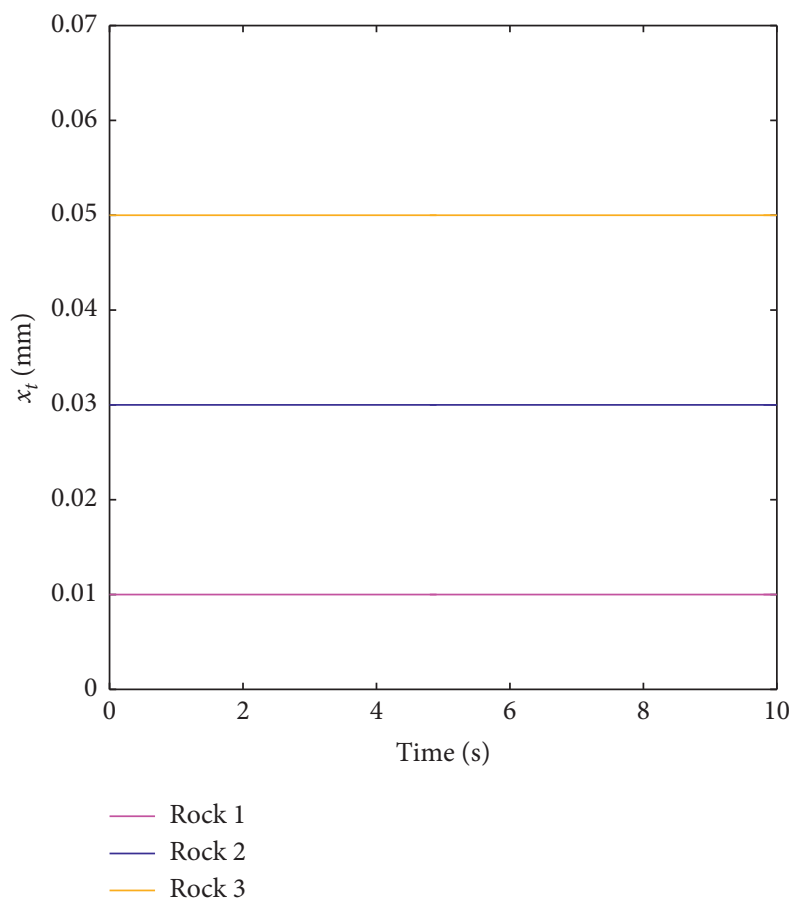

FIGURE 2: Changes of vibration displacement of different rocks with time.

TABLE 1: Calculation parameters.

\begin{tabular}{|c|c|c|c|c|c|c|}
\hline Number & $K(\mathrm{~N} / \mathrm{m})$ & $\Omega(\mathrm{rad} / \mathrm{s})$ & $C(\mathrm{~N} \cdot \mathrm{m} / \mathrm{s})$ & $m(\mathrm{~kg})$ & $F(\mathrm{~N})$ & $P_{r}(\mathrm{~N})$ \\
\hline 1 & 1 & & & & & \\
\hline 2 & 2 & 100 & 0.5 & 0.5 & 1000 & 3000 \\
\hline 3 & 3 & & & & & \\
\hline
\end{tabular}

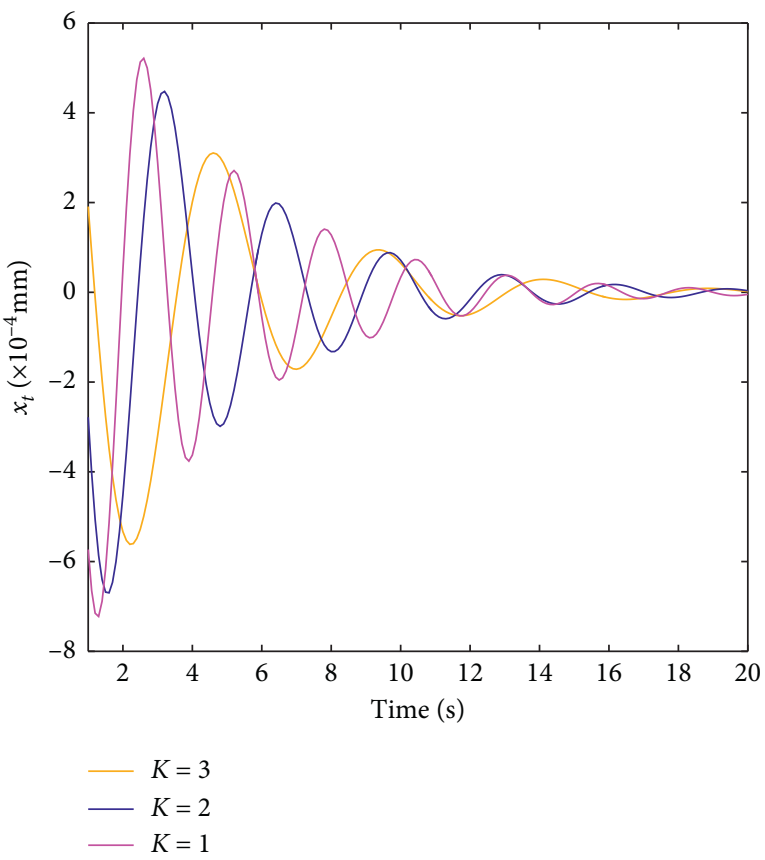

(a)

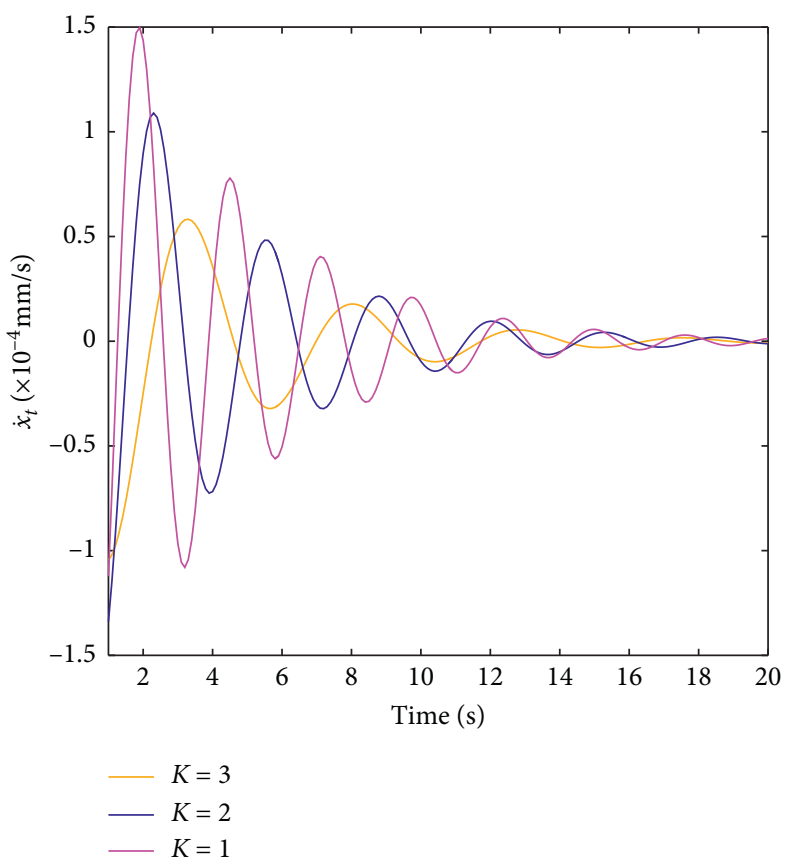

(b)

Figure 3: Changes of movement displacement (a) and movement velocity (b) of rock surface with time in different $k$. 
TABLE 2: Calculation parameters.

\begin{tabular}{lcccccr}
\hline Number & $C(\mathrm{~N} \cdot \mathrm{m} / \mathrm{s})$ & $\Omega(\mathrm{rad} / \mathrm{s})$ & $K(\mathrm{~N} / \mathrm{m})$ & $m(\mathrm{~kg})$ & $F(\mathrm{~N})$ & $P_{r}(\mathrm{~N})$ \\
\hline 1 & 0.5 & & & & & \\
2 & 1 & 100 & 1 & 0.5 & 1000 & 3000 \\
3 & 1.5 & & & & & \\
\hline
\end{tabular}

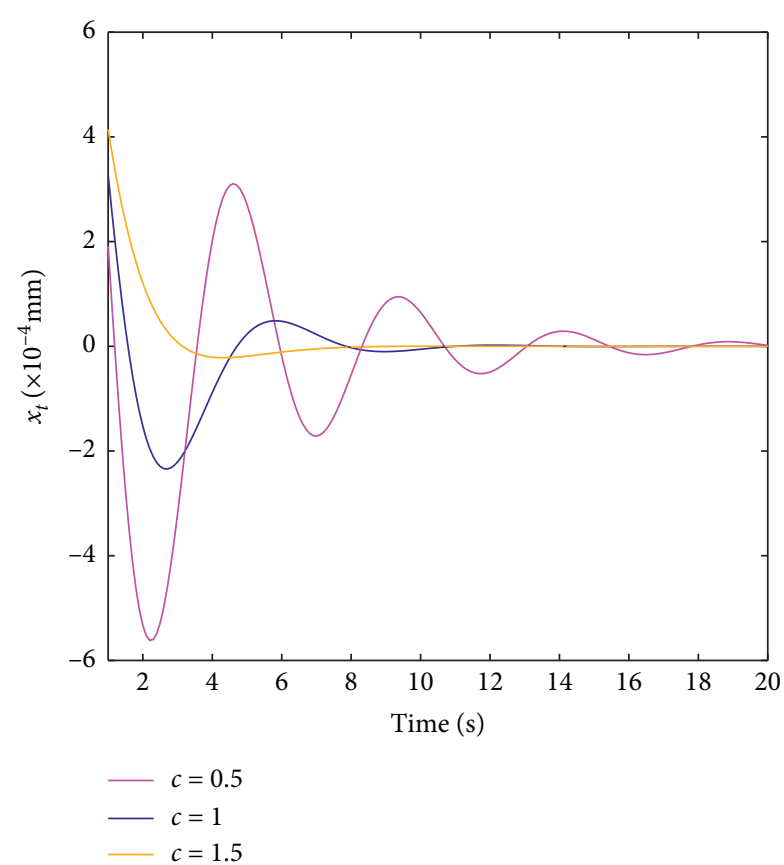

(a)

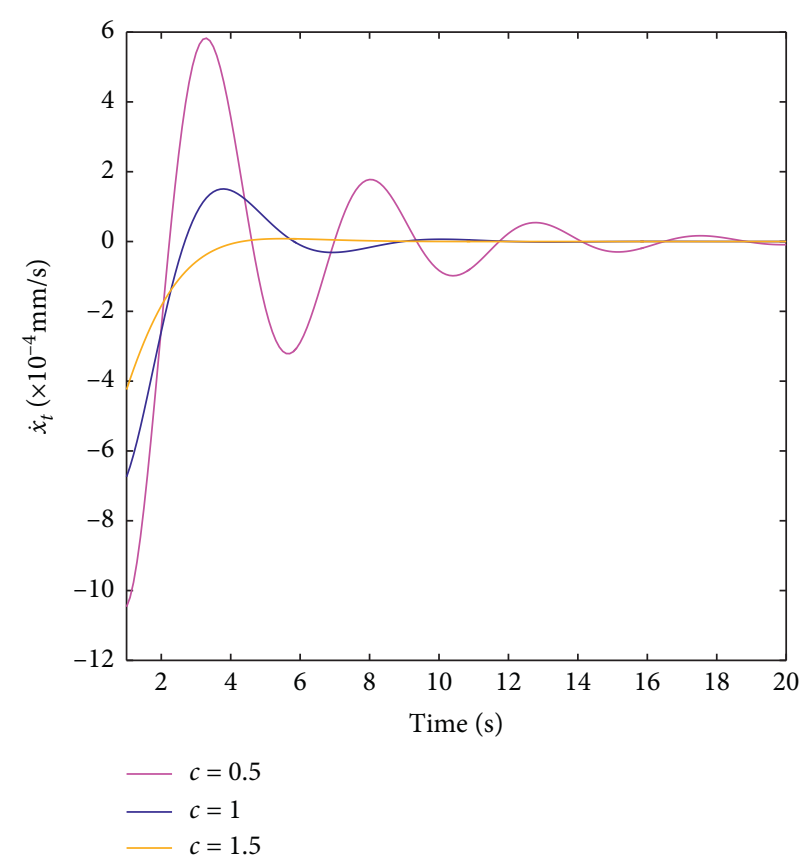

(b)

FIGURE 4: Changes of movement displacement (a) and movement velocity (b) of rock surface with time in different $c$.

TABLE 3: Calculation parameters.

\begin{tabular}{lcccccc}
\hline Number & $\Omega(\mathrm{rad} / \mathrm{s})$ & $C(\mathrm{~N} \cdot \mathrm{m} / \mathrm{s})$ & $K(\mathrm{~N} / \mathrm{m})$ & $m(\mathrm{~kg})$ & $F(\mathrm{~N})$ & $P_{r}(\mathrm{~N})$ \\
\hline 1 & 50 & & & & & \\
2 & 100 & 0.5 & 1 & 0.5 & 1000 & 3000 \\
3 & 200 & & & & & \\
\hline
\end{tabular}

As shown in Figure 7(a), the smaller the rock damping, the greater the movement displacement produced by the rock surface with time. This movement lasts until all the impact energy is consumed and the rock surface stops moving. Plastic deformation occurs with a large rock damping, and the movement displacement is very small.

As shown in Figure 7(b), the smaller the critical force is, the easier it is for a rock to reach its plastic deformation condition and produce a large displacement. On the contrary, when the displacement of the rock surface is smaller, the slider stops moving until the impact force no longer reaches the critical force of the rock.

\section{Numerical Simulation of Harmonic Impact Drilling}

4.1. Modeling and Solution. In this study, the ABAQUS software is used to simulate the drilling process for analyzing the performance of the harmonic impact drilling. In order to match the actual drilling situation, the finite element model includes rotary table, drill pipe, bottom-hole assembly, drill bit, and rock, as shown in Figure 8.

As shown in Figure 8, the drill bit is five-blade PDC bit and the rock is limestone. In the model, a constant angular velocity is applied to the rotary table, and a WOB and 


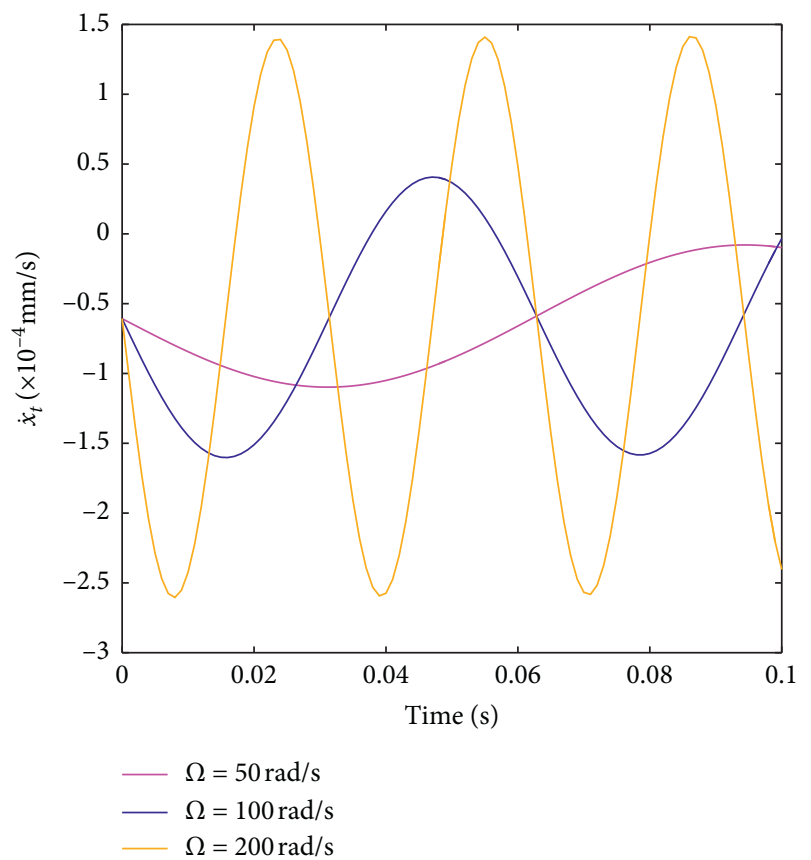

FIgURE 5: Changes of movement velocity of rock surface with time in different $\Omega$.

TABLE 4: Calculation parameters.

\begin{tabular}{lccccr}
\hline Number & $F(\mathrm{~N})$ & $C(\mathrm{~N} \cdot \mathrm{m} / \mathrm{s})$ & $K(\mathrm{~N} / \mathrm{m})$ & $m(\mathrm{~kg})$ & $\Omega(\mathrm{rad} / \mathrm{s})$ \\
\hline 1 & 1000 & & & & \\
2 & 2000 & 0.5 & 1 & 0.5 & 100 \\
3 & 3000 & & & & 3000 \\
\hline
\end{tabular}

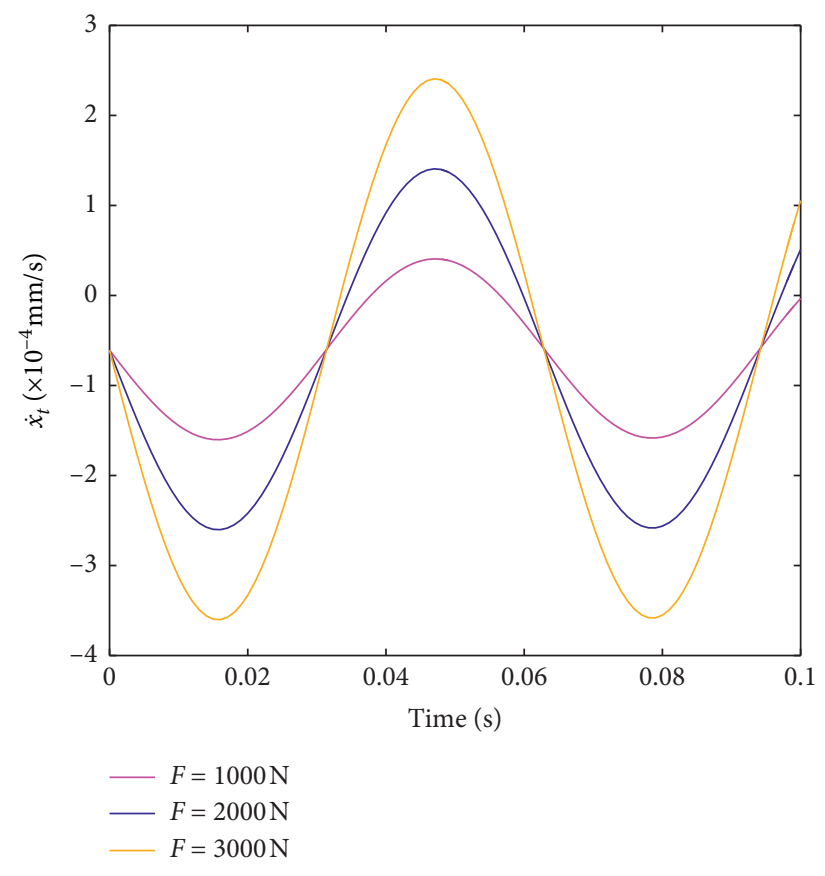

FIGURE 6: Changes of movement velocity of rock surface with time in different $F$. 
TABLE 5: Calculation parameters.

\begin{tabular}{lcccccc}
\hline Number & $C(\mathrm{~N} \cdot \mathrm{m} / \mathrm{s})$ & $F(\mathrm{~N})$ & $K(\mathrm{~N} / \mathrm{m})$ & $m(\mathrm{~kg})$ & $\omega(\mathrm{rad} / \mathrm{s})$ & $P_{r}(\mathrm{~N})$ \\
\hline 1 & 0.5 & & & & & 100 \\
2 & 1 & 1000 & 1 & 0.5 & 100 & 200 \\
3 & 1.5 & & & & 300 \\
\hline
\end{tabular}

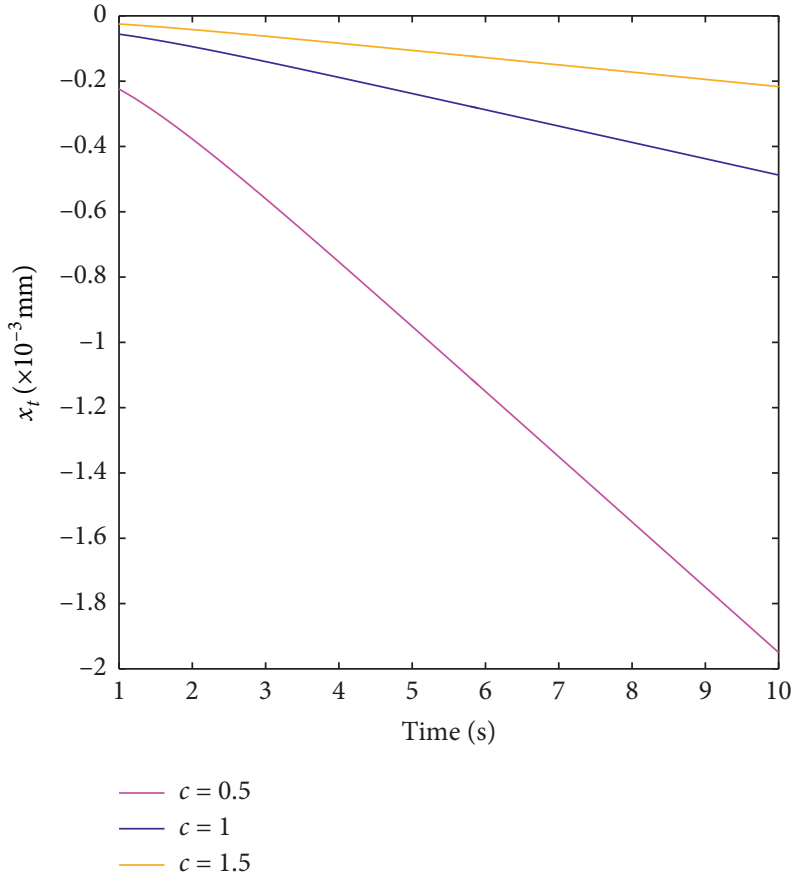

(a)

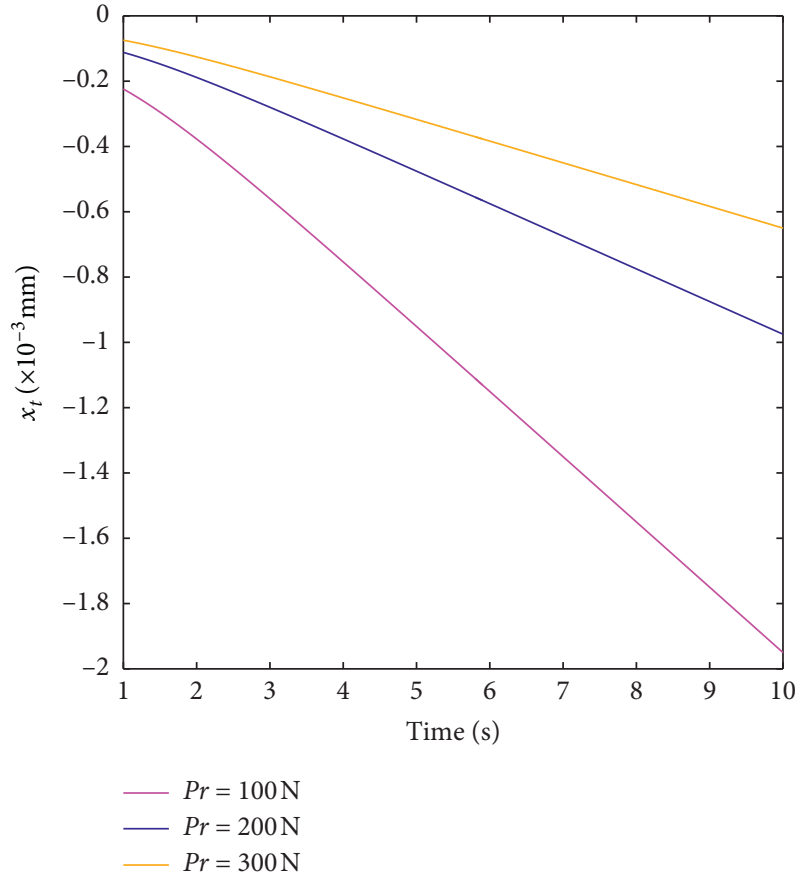

(b)

Figure 7: Changes of movement displacement of rock surface with time in different $c$ (a) and $P_{r}$ (b).

harmonic dynamic load are exerted on the BHA and drill bit, respectively. In addition, the whole model is constrained in the $X$ direction and the bottom of the rock is fixed with all directions. To make the simulation more accurate, the teeth of the PDC bit and parts of the rock which contact the drill bit are meshed more finely than other parts. The specific drilling parameters and rock characteristics parameters are given in Tables 6 and 7 .

4.2. Results and Discussion. In the simulation process, no impact force is exerted in conventional drilling compared with harmonic impact drilling. The following discussion on the simulation results will be carried out from the perspective of axial motion and torsional motion of the drill bit.

4.2.1. Axial Motion. In Figures 9 and 10, the axial drilling characteristics of conventional drilling and harmonic impact drilling are presented. As shown in Figure 9, in both drilling methods, the progression of the drill bit increases in a stepwise form with the increase of time due to the stick-slip effect.

It can be obtained from the simulation results that, under the same drilling conditions, the maximum rate of penetration (ROP) is $39.59 \mathrm{~mm} / \mathrm{s}$ and the average ROP is
$5.58 \mathrm{~mm} / \mathrm{s}$ in the conventional drilling, which are corresponding to $54.77 \mathrm{~mm} / \mathrm{s}$ and $8.56 \mathrm{~mm} / \mathrm{s}$ in the harmonic impact drilling, respectively. It is surprising to note that the average ROP is increased by $46.3 \%$, which obviously reveals that the harmonic impact significantly improves the axial drilling efficiency.

In addition, it can also be got from Figure 10 that the maximum reverse velocity is $15.94 \mathrm{~mm} / \mathrm{s}$ in the conventional drilling, while that is $12.17 \mathrm{~mm} / \mathrm{s}$ in the harmonic impact drilling. What is more, the stability of axial ROP of harmonic impact drilling is better than that of conventional drilling. It is intuitive that the harmonic impact alleviates the phenomenon of bit bounce, which further demonstrates that harmonic impact drilling can improve the axial drilling performance and achieve the purpose of increasing ROP.

4.2.2. Torsional Motion. Figures 11 and 12 show the torsional drilling characteristics of conventional drilling and harmonic impact drilling, respectively. As can be seen from Figure 11, compared with the conventional drilling, the rotational angular velocity of the drill bit in the harmonic impact drilling decreases, but the degree is only $3.4 \%$. However, from the perspective of the stability of angular velocity, the standard deviation of angular velocity of 


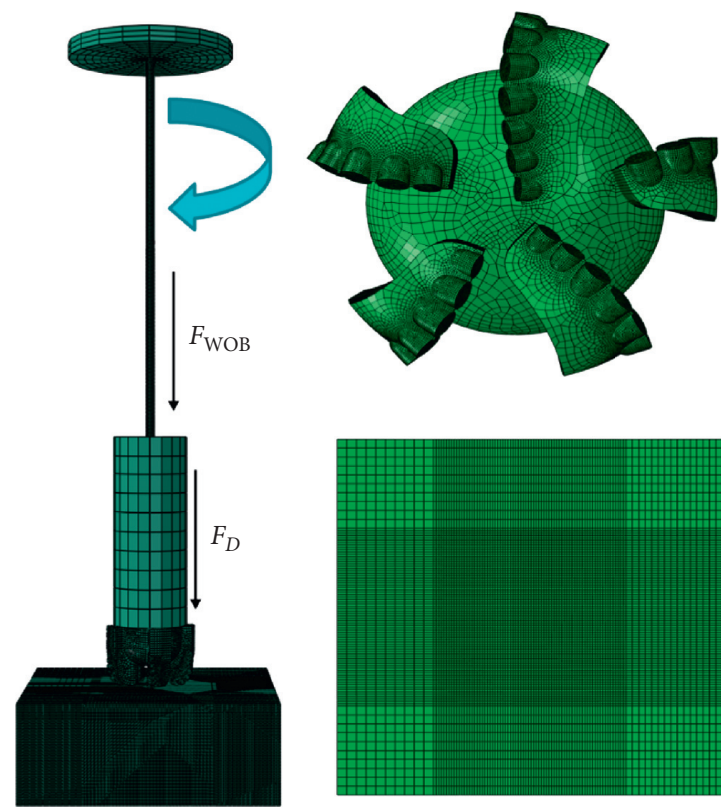

FIGURE 8: The finite element model of drilling process

TABLE 6: Drilling parameters.

\begin{tabular}{lcccc}
\hline Parameters & Angular velocity $(\mathrm{rad} / \mathrm{s})$ & WOB $(\mathrm{kN})$ & Impact force $(\mathrm{kN})$ & Impact frequency $(\mathrm{Hz})$ \\
\hline Values & 4.7 & 15 & 7.5 & 100 \\
\hline
\end{tabular}

TABLE 7: Characteristics parameters of limestone.

\begin{tabular}{lcccccc}
\hline Parameters & Density $\left(\mathrm{t} / \mathrm{mm}^{3}\right)$ & Elastic modulus $(\mathrm{MPa})$ & Poisson's ratio & Yield strength $(\mathrm{MPa})$ & Friction angle & Fracture strain \\
\hline Values & $2.75 \times 10^{-9}$ & 51500 & 0.33 & 120 & 30.16 & 0.075 \\
\hline
\end{tabular}

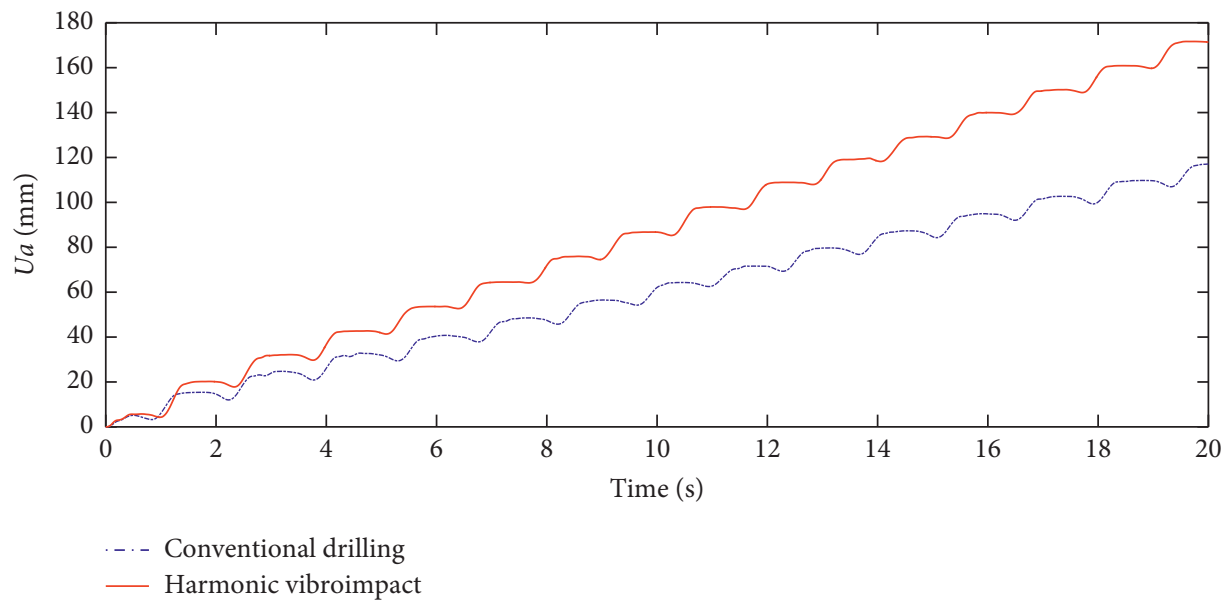

FIGURE 9: Time-history curves of progression under different drilling conditions.

conventional drilling is $6.2 \mathrm{rad} / \mathrm{s}$, which is $5.7 \mathrm{rad} / \mathrm{s}$ of harmonic impact drilling. This confirms that the angular velocity of drill bit under harmonic vibroimpact is more stable. Furthermore, it is important to note that the stability is mainly reflected in the stickiness stage of the drill bit. It can be observed that not only is the stickiness stage shortened, but also the phenomenon of reverse rotation is alleviated.

Based on the analysis of the angular acceleration in Figure 12, we can also come to similar conclusions that the average angular acceleration is higher and the standard 


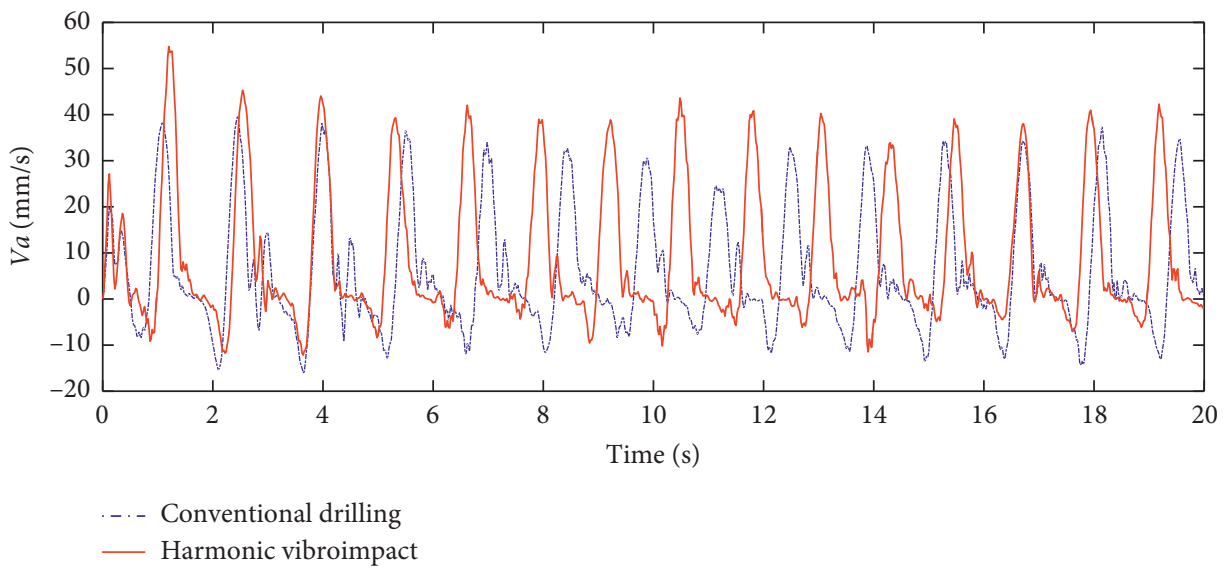

FIGURE 10: Time-history curves of ROP under different drilling conditions.

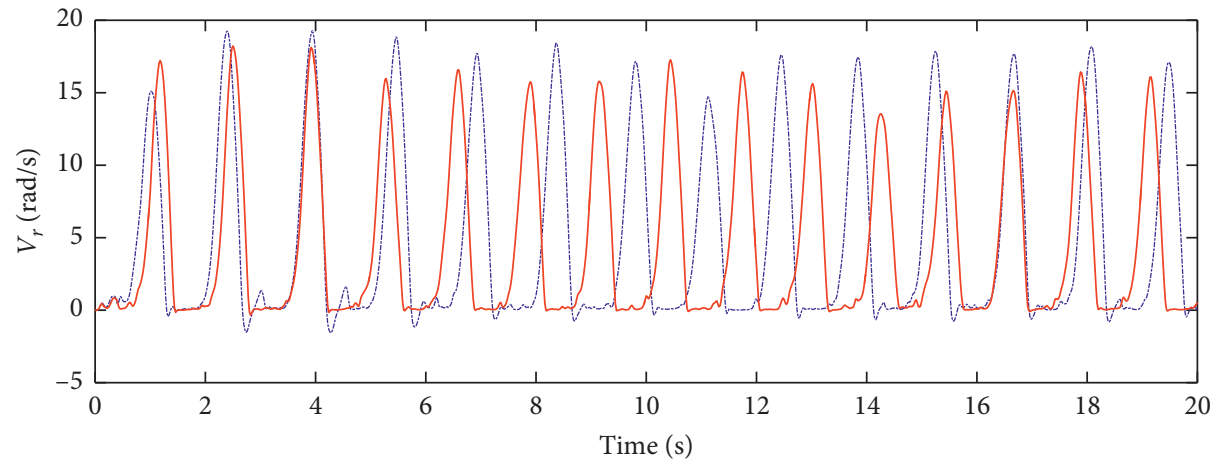

-..- Conventional drilling

- Harmonic vibroimpact

FIGURE 11: Time-history curves of angular velocity under different drilling conditions.

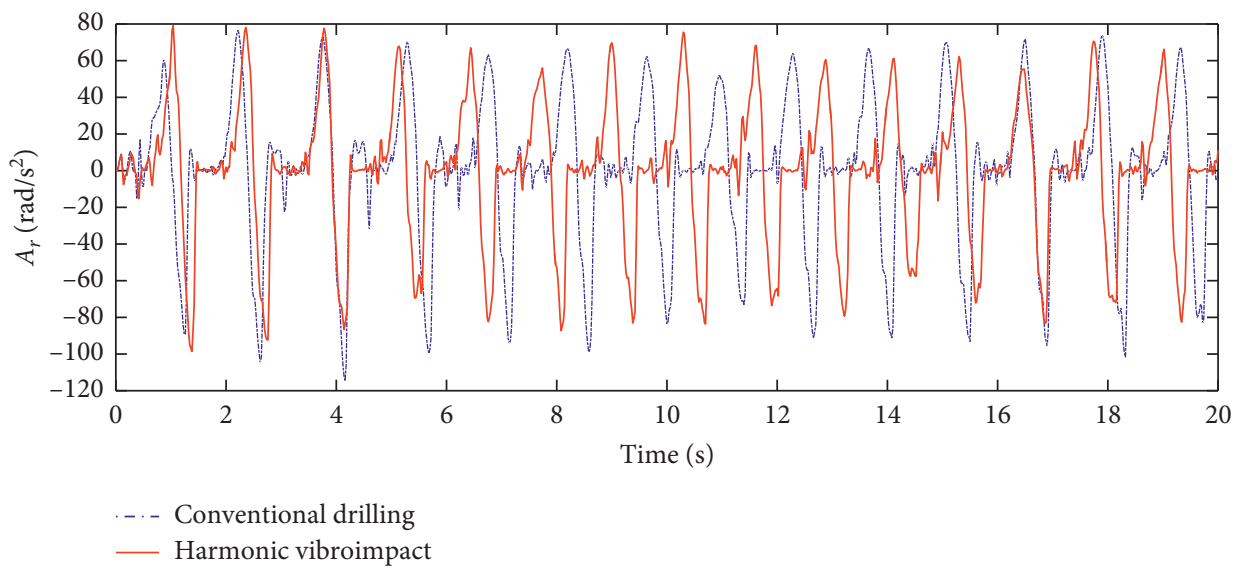

FIGURE 12: Time-history curves of angular acceleration under different drilling conditions. 
deviation of angular acceleration is lower of harmonic impact drilling compared to those of conventional drilling. The simulation results demonstrate that harmonic impact not only does not reduce the cutting effect of the drill bit but also mitigates its stick-slip problem to some extent, therefore making the cutting performance of the drill bit more stable and efficient.

\section{Conclusion}

(1) According to the analysis of the three motions of the drill bit and the rock based on the model, it can be seen that the rock can produce motion under the excitation of simple harmonic vibration. The motion state can be divided into three stages: the drill bit does not contact the rock, the drill bit contacts the rock but does not drill, and the drill bit drills into the rock. Its motion state is affected by rock stiffness, damping, critical force, dynamic excitation force, and excitation frequency.

(2) According to the numerical calculation, when the drill bit is in contact with the rock but no drilling occurs, the rock motion presents harmonic vibration with simple harmonic vibration impact. The smaller the stiffness of the rock is, the smaller the damping is, the closer the excitation frequency is to the natural frequency of the rock, and the greater the dynamic excitation force is, and the greater the displacement and velocity of the surface are. In the drilling stage, the smaller the rock damping is, the smaller the critical force is, and the more prone the rock is to plastic collapse. The displacement of the surface is approximately linear.

(3) The numerical simulations have been carried out to analyze the performance of the harmonic impact drilling. The results demonstrate that the harmonic impact can not only improve the ROP and alleviate bit bounce in the axial direction but also shorten the sticking time and slow down the reversal phenomenon of the drill bit in the torsional cutting direction, which will help to improve the drilling efficiency of the drill bit. The results can also be further verified by the conclusions of $\mathrm{Li}[16,17]$ and Wiercigroch [12], in which the rate of penetration in the harmonic impact drilling has been increased by more than $80 \%$ $[21,22]$.

\section{Data Availability}

The $((15.94 \mathrm{~mm} / \mathrm{s}$ and $12.17 \mathrm{~mm} / \mathrm{s})$, and $(46.3 \%))$ data used to support the findings of this study are included within the article.

\section{Conflicts of Interest}

The authors declare that they have no conflicts of interest.

\section{Acknowledgments}

This study was supported by the Open Fund of State Key Laboratory of Shale Oil and Gas Enrichment Mechanisms and Effective Development (10010099-19-ZC0607-0046). The authors also would like to acknowledge the preliminary work by Siqi Li.

\section{References}

[1] M. Wiercigroch, "Resonance enhanced drilling: method and apparatus," Patent No.WO2007141550, 2007.

[2] M. Wiercigroch, "Drilling aparatus," Patent PCT/EP2014/ 071701, 2014.

[3] R. R. Aguiar and H. I. Weber, "Development of a vibroimpact device for the resonance hammer drilling," in Proceedings of the XII International Symposium on Dynamic Problems of Mechanics, Illhabela, Brazil, January 2007.

[4] E. Pavlovskaia, M. Wiercigroch, K. C. Woo, and A. A. Rodger, "Modelling of ground moling dynamics by an impact oscillator with a frictional slider," Meccanica, vol. 38, no. 1, pp. 85-97, 2003.

[5] W. Yang, L. I. Lei, Y. Zhao et al., "Preliminary inquiry of theory of resonance rock breaking," Energy Technology and Management, vol. 4, pp. 7-9, 2007.

[6] O. Ajibose, M. Wiercigroch, E. Pavlovskaia et al., "Drifting impact oscillator with a new model of the progression phase," Journal of Applied Mechanics, vol. 79, pp. 1-9, 2012.

[7] A. D. Batako, V. I. Babitsky, and N. A. Halliwell, "Modelling of vibro-impact penetration of self-exciting percussive-rotary drill bit," Journal of Sound and Vibration, vol. 271, no. 1-2, pp. 209-225, 2004.

[8] E. Pavlovskaia, D. C. Hendry, and M. Wiercigroch, "Modelling of high frequency vibro-impact drilling," International Journal of Mechanical Sciences, vol. 91, pp. 110-119, 2014.

[9] W. Marian, M. K. Anton, and W. Jerzy, "Vibrational energy transfer via modulated impacts for percussive drilling," Journal of Theoretical and Applied Mechanics, vol. 46, no. 3, pp. 715-726, 2008.

[10] O. K. Ajibose, M. Wiercigroch, E. Pavlovskaia, and A. R. Akisanya, "Global and local dynamics of drifting oscillator for different contact force models," International Journal of Non-linear Mechanics, vol. 45, no. 9, pp. 850-858, 2010.

[11] L. F. P. Franca and H. I. Weber, "Experimental and numerical study of a new resonance hammer drilling model with drift," Chaos, Solitons \& Fractals, vol. 21, no. 4, pp. 789-801, 2004.

[12] M. Wiercigroch, V. Vaziri, and M. Kapitaniak, "RED: Revolutionary drilling technology for hard rock formations," in Proceedings of the SPE/IADC Drilling Conference and Exhibition, SPE-17DC-P-382-SPE/IADC-MS, The Hague, The Netherlands, March 2017.

[13] S. Li, S. Tian, W. Li et al., "Research on the resonance characteristics of rock under harmonic excitation," Shock and Vibration, vol. 2019, Article ID 6326510, 11 pages, 2019.

[14] S. Li, in Proceedings of the IOP Conference Series: Earth and Environmental Science, vol. 570, Article ID 022036, Yogyakarta, Indonesia, October 2020.

[15] W. Li, T. Yan, L. Siqi, and X. Zhang, "Rock fragmentation mechanisms and an experimental study of drilling tools during high-frequency harmonic vibration," Petroleum Science, vol. 10, no. 2, pp. 205-211, 2013.

[16] S. Li, V. Vaziri, M. Kapitaniak, J. M. Millett, and M. Wiercigroch, "Application of resonance enhanced drilling 
to coring," Journal of Petroleum Science and Engineering, vol. 188, Article ID 106866, 2020.

[17] S. Li, T. Yan, W. Li et al., "Mechanisms experimental study of rock breaking assisted with high frequency harmonic vibration and impaction," Journal of China University of Petroleum, vol. 39, no. 4, pp. 85-91, 2015.

[18] M. Wiercigroch, J. Wojewoda, and A. M. Krivtsov, "Dynamics of ultrasonic percussive drilling of hard rocks," Journal of Sound and Vibration, vol. 280, no. 3-5, pp. 739-757, 2005.

[19] S. Li, T. Yan, W. Li, and F. Bi, "Simulation on vibration characteristics of fractured rock," Rock Mechanics and Rock Engineering, vol. 49, no. 2, pp. 515-521, 2016.

[20] J. Tian, Z. Yang, C. Fu et al., "Calculation method of rockbreaking behavior under impact vibration of high frequency and micro amplitude," vol. 45, no. 6, pp. 1808-1816, 2015.

[21] L. I. Si-qi, T. Yan, L. I. Wei et al., "Modeling of vibration response of rock by harmonic impact," Journal of Natural Gas Science and Engineering, vol. 23, pp. 90-96, 2015.

[22] L. Hu, W. Zhang, and J. Zhu, "Structural topology optimization and frequency influence analysis under harmonic force excitations," Chinese Journal of Theoretical and Applied Mechanics, vol. 45, no. 4, pp. 588-597, 2013. 